\title{
Prevalence of human herpesviruses in biliary fluid and their association with biliary complications after liver transplantation
}

Conrad Rauber ${ }^{1,5^{*}}$ (D), Katja Bartelheimer ${ }^{1}$, Taotao Zhou ${ }^{1}$, Christian Rupp ${ }^{1}$, Paul Schnitzler ${ }^{3}$, Peter Schemmer ${ }^{2,4}$, Peter Sauer ${ }^{1}$, Karl Heinz Weiss ${ }^{1}$ and Daniel Nils Gotthardt ${ }^{1}$

\begin{abstract}
Background: Beta-herpesviruses are common opportunistic pathogens that cause morbidity after liver transplantation (LT).

Methods: Objective of the study was to evaluate the prevalence and correlation of herpesviruses in bile, blood and liver tissue and to investigate their association with biliary complications and retransplantation (re-LT) free survival after LT.

The study design is a single-center case-control study. We performed quantative polymerase chain reaction (qPCR) for herpesvirus 1-8 DNA in bile, blood and liver tissue of 73 patients after first LT and analyzed their clinical courses retrospectively.

Results: The median follow-up was 48 months (range 2-102), during which a total of 16 patients underwent re-LT and 11 patients died. Of the patients, $46.5 \%$ received valganciclovir prophylaxis at the time of bile sample acquisition. Cytomegalovirus (CMV) (18.3\%), human herpesvirus 6 (HHV-6) (34.2\%), human herpesvirus 7 (HHV-7) (20.5\%) and Epstein-Barr virus (EBV) (16.4\%) were highly prevalent in bile after LT, while herpes simpex virus 1 and 2 (HSV-1, HSV-2), varicella-zoster virus (VZV) and human herpesvirus 8 (HHV-8) were not or rarely detected in bile. Valganciclovir prophylaxis did not reduce the prevalence of HHV-6 and HHV-7 in bile, but it did reduce the presence of CMV and EBV. The presence of HHV-6 in bile was associated with non-anastomotic biliary strictures (NAS) and acute cellular rejection (ACR).

Conclusions: CMV, EBV, HHV-6 and HHV-7 are more prevalent in biliary fluid than in liver biopsy or blood serum after LT. HHV-6 and HHV-7 might be associated with biliary complications after LT. Biliary fluids might be an attractive target for routine herpesvirus detection.
\end{abstract}

Keywords: Herpesvirus, HHV-6, Bile, Stricture, Non-anastomotic stricture, Liver transplantation, Complication

\footnotetext{
*Correspondence: conrad.rauber@gmx.de

'Department of Gastroenterology and Hepatology, University Hospital

Heidelberg, Heidelberg, Germany

${ }^{5}$ INSERM U1015, Gustave Roussy Comprehensive Cancer Institute, Villejuif,

France

Full list of author information is available at the end of the article
}

(c) The Author(s). 2019 Open Access This article is distributed under the terms of the Creative Commons Attribution 4.0 International License (http://creativecommons.org/licenses/by/4.0/), which permits unrestricted use, distribution, and reproduction in any medium, provided you give appropriate credit to the original author(s) and the source, provide a link to the Creative Commons license, and indicate if changes were made. The Creative Commons Public Domain Dedication waiver (http://creativecommons.org/publicdomain/zero/1.0/) applies to the data made available in this article, unless otherwise stated. 


\section{Background}

Liver transplantation (LT) is to date the only curative option for patients with end-stage liver disease. Liver transplantation requires lifelong immunosuppression to prevent allograft rejection and subsequent graft failure. Immunosuppression predisposes solid organ recipients to various opportunistic infections. The role of many of these opportunistic pathogens in the development of complications after LT is unknown. Human herpesviruses (HHV) 1-8 are enveloped, double-stranded DNA and human host specific viruses that proliferate in lymphocytes and neuronal or epidermal cells. They can persist lifelong in the host and reactivate under circumstances of immunosuppression. Active disease can be detected by polymerase chain reaction (PCR) of HHV 1-8 DNA [1]. The incidence of Cytomegalovirus (CMV), HHV-6 and HHV-7 in blood after LT has been reported as high as 70,33 and $42 \%$, respectively [2]. CMV is the most common infectious pathogen after LT [3] and can infect various organs, including the allograft itself. CMV in bile has been associated with early graft loss and biliary complications after LT [4]. HHV-6 and HHV-7, together with CMV (HHV-5), comprise the group of beta-herpesviruses. Human herpesvirus 6 has been linked to hepatitis post LT, but most HHV-6 infections after LT are asymptomatic $[5,6]$. The presence of HHV-6 and HHV-7 viremia in blood after LT has inconsistently been linked to reduced graft survival. However, detecting HHV-6 DNA in liver biopsies has been associated with graft hepatitis and reduced graft survival [79]. Epstein-Barr virus (EBV) and CMV detection in liver biopsies had no effect on overall survival after LT [7]. To prevent the reactivation of CMV after LT, patients receive valganciclovir chemoprophylaxis for three to 6 months after LT [10]. For HHV-6 and -7 , there are no recommendations for prevention. In vitro, HHV-6 and HHV-7 are less susceptible to ganciclovir than CMV [11]. The objective of this study was to examine the association between herpesviruses in different body fluids and tissues after LT and to elucidate their role in graft complications after LT.

\section{Methods}

\section{Study population}

In this single-center case-control study, patients were selected retrospectively out of all adult patients who underwent a first liver transplantation at the University Hospital Heidelberg between January 2007 and July 2015, for which period bile samples were available in our biobank $(n=215)$. Exclusion criteria were death within 30 days after transplantation, risk factors for ischemic bile duct injury such as hepatic artery stenosis, portal vein stenosis or portal vein thrombosis $(n=84)$, insufficient sample volume $(n=53)$ and primary hepaticojejunostomy $(n=5)$. Of the remaining 73 patients, we included bile samples for 37 patients with NAS, 20 patients with AS and 16 without stricture (Fig. 1). 19 patients had developed acute cellular rejection after LT of which 13 were diagnosed before and 6 after ERC.

\section{Sample acquisition}

Bile samples were retrieved from ERC examinations, immediately frozen and stored at a temperature of $-80^{\circ} \mathrm{C}$. Indications for ERC in all patients were abnormal liver laboratory values. Indications for liver biopsies were suspected allograft rejection or infection. Samples were formalin-fixed, paraffin-embedded and stored appropriately. Blood samples were taken routinely for check-up or if clinically indicated and stored at $-20^{\circ} \mathrm{C}$.

\section{Immunosuppressive and chemoprophylactic regime}

All patients received corticosteroids for 6 months after transplantation. Additionally, a calcineurin inhibitor (CNI) (ciclosporin or tacrolimus) was administered, beginning within the first days after transplantation. Mycophenolate (MMF) was either started directly after transplantation (de novo), or after 21 days (delayed). Infectious complications led to discontinuation of MMF, according to internal clinical guidelines. Prophylaxis for CMV infection with valganciclovir was administered to all patients within the first 3 to 6 months after transplantation at a dose of $900 \mathrm{mg}$ once daily (both CMV IgG seropositive donor/recipient matches did not receive CMV prophylaxis).

\section{Transplant allocation criteria}

All patients were transplanted within the Eurotransplant allocation system in Germany [12]. Patients were transplanted according to the model of end-stage liver disease (MELD) score, which is based on the recipient's kidney function, coagulation time and serum bilirubin and ranges from 6 to 40 [13]. Patients transplanted for hepatocellular carcinoma were granted an exceptional MELD score (eMELD) in which the allocation is based on waiting time [14].

\section{Clinical follow-up}

The clinical records of the patients were reviewed in our electronic patient database (i.s.h. med, SAP, Germany). We recorded demographic data, underlying diseases and the reasons for transplantation, immunosuppressive regimen and antiviral prophylaxis, infectious complications such as herpesvirus infections, biliary complications, incidence of acute or chronic graft rejection, information on graft, donor and recipient hepatitis- and CMV-status and recipient post- and perioperative values. All patients were followed until death or retransplantation or until October 1, 2015. 


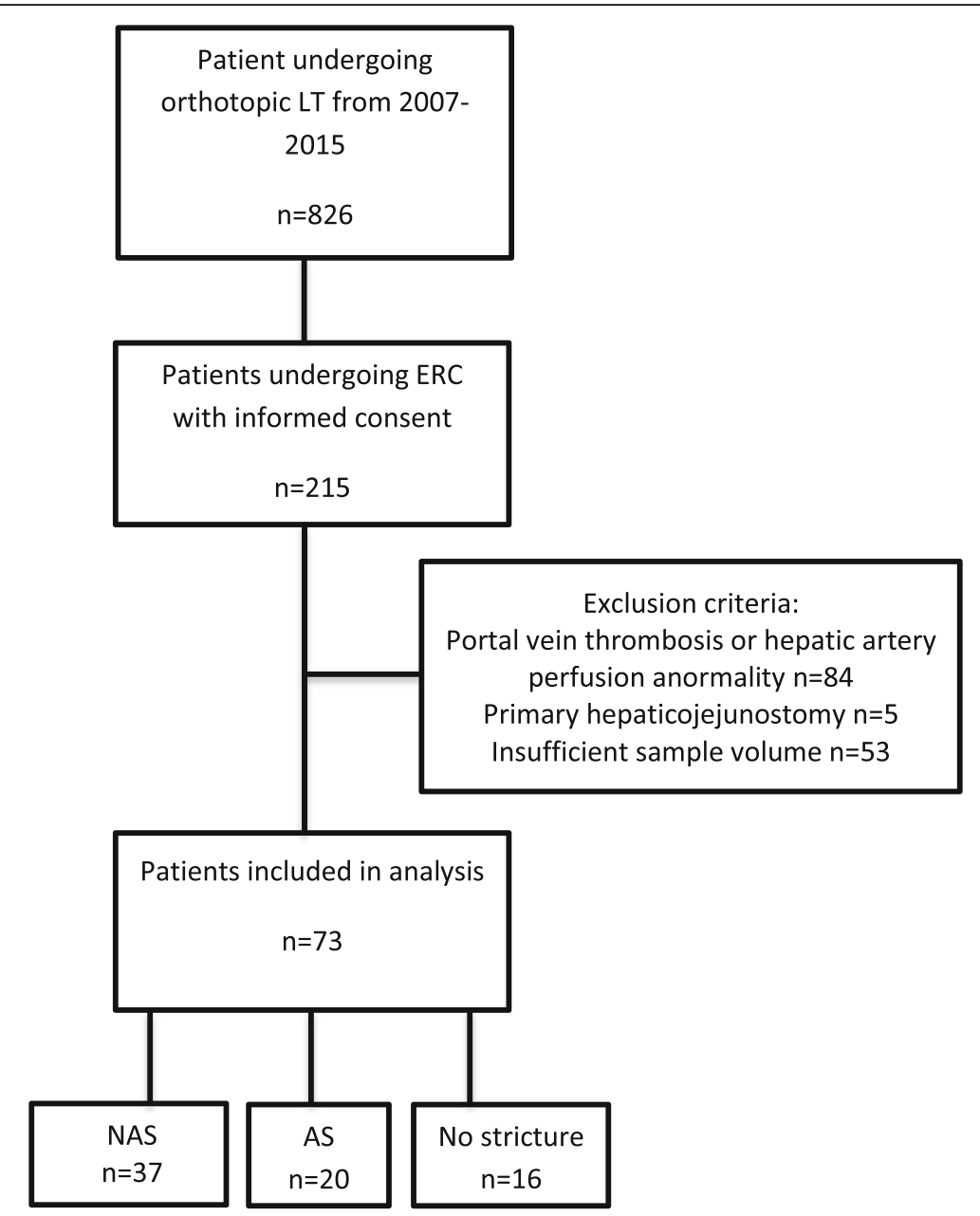

Fig. 1 Flowchart of patients' inclusion in the analysis. AS- anastomotic stricture, LT- liver transplantation, NAS - non-anastomotic stricture

\section{Detection of herpesvirus-DNA in bile, blood and liver} tissue

DNA extraction. Herpesvirus-DNA was extracted from $400 \mu \mathrm{l}$ of bile and $200 \mu \mathrm{l}$ of serum using QIAamp DNA blood mini-kit (Qiagen, Germany). To extract DNA from the formalin-fixed paraffin-embedded liver biopsies, the QIAamp DNA FFPE tissue kit (Qiagen, Germany) was used. Both serum and bile samples were stored at $-80^{\circ} \mathrm{C}$, and extracted DNA was temporarily stored at $-20^{\circ} \mathrm{C}$. The DNA concentration after extraction was measured with a Colibri microvolume spectrometer (Titertek-Berthold, Germany).

Quantitative real time polymerase chain reaction (qPCR). Virus-specific r-gene quantification kits (Biomerieux, France) were used to prepare the extracted DNA for quantification. The kit contains an internal control that was added to the samples before DNA extraction to monitor the extraction process and the presence of amplification inhibitors. Appropriate negative controls were performed to check for contamination along the extraction and amplification process. Quantification standards were available for
HHV 1-6 allowing the measurement of the viral DNA load. The detection of HHV-7 was qualitative, and the HHV-7 viral count could not be quantified. PCR was performed using the LightCycler 480 (Roche Diagnostics, Switzerland).

\section{Statistical analysis}

Descriptive statistics were used to characterize patients' demographics and clinical variables. Continuous variables are expressed as mean values with standard deviation (SD), non-normally distributed variables as median values with range and categorical variables as number and percent. A chi-square test was used to compare the frequency of differences in patient characteristics, complications and medical regimens according to herpesvirus detection in bile. Statistical data was analyzed using SPSS (SPSS 22.0 Inc., USA).

\section{Results}

Total population

The clinical baseline characteristics of LT subjects are summarized in Table 1. 
The median follow-up was 48 months (range 2-102) (Table 1). A total of 16 patients underwent re-LT at a median time of 11 months (range 1-42), and 11 patients died during follow-up after a median time of 15.2 months (range 7-37), with follow-up terminating at the combined endpoint of re-LT or death. The average age of LT recipients was 56 (range 30-69) years. Recipients were predominantly male $(79.5 \%)$, and the most frequent indication for LT was alcoholic cirrhosis (34.5\%). Donors were slightly older with a mean age of 67 (range 21-88) years, while gender was evenly distributed $(48.6 \% \mathrm{fe}$ male). The ERC from which bile was retrieved occurred at a median of 3.4 months (range $0.3-73$ ) after LT. At time of ERC, $46.5 \%$ of patients were receiving valganciclovir as cytomegalovirus prophylaxis (900 mg per day).

Table 1 Characteristics of patients who underwent LT. Data is given as mean $( \pm \mathrm{SD})$, median (range) or number (\%), as appropriate

\begin{tabular}{ll}
\hline Number of patients & 73 \\
Gender recipient, female & $15(20.5 \%)$ \\
Gender donor, female & $36(49.3 \%)$ \\
Recipient age, years, (median, range) & $56(30-69)$ \\
Donor age, years, (median, range) & $67(21-88)$ \\
Follow-up, months, (median, range) & $48(2-102)$ \\
Child-Turcotte-Pugh score (A/B/C) at LT, n & $25 / 16 / 31$ \\
Valganciclovir prophylaxis at time of ERC & $34(47.1 \%)$ \\
Time of ERC, months since LT, (median, range) & $3.4(0.3-73)$ \\
Lab/eMELD at LT (mean \pm SD) & $27.0 \pm 8.7$ \\
Cold ischemia time, hours (mean \pm SD) & $10.0 \pm 2,64$ \\
Indication & \\
Alcoholic cirrhosis & $23(31.5 \%)$ \\
$\quad$ Hepatitis B & $2(2.7 \%)$ \\
Hepatitis C & $11(15.1 \%)$ \\
HCC & $15(20.5 \%)$ \\
PSC & $2(2.7 \%)$ \\
Cryptogenic & $7(9.6 \%)$ \\
Other & $13(17.8 \%)$ \\
Death during follow-up & $11(15.1 \%)$ \\
Retransplantation & $16(21.9 \%)$ \\
Taclosporin de novo & $51(69.9 \%)$ \\
hepatocellular carcinoma, LT liver transplantation, labMELD laboratory model \\
of end-stage liver disease, PSC primary sclerosing cholangitis
\end{tabular}

All patients received immunosuppression at time of ERC, and all but two patients received calcineurin inhibitors (CNI) de novo (69.9\% ciclosporin, 30.1\% tacrolimus), while $83.6 \%$ received additional mycophenolate mofetil. Neither the time between LT and ERC nor the immunosuppressive regimen at ERC significantly influenced the rate of herpesvirus positivity in bile.

We tested ERC bile samples for herpesvirus 1-8. For 42 patients concordant serum samples were available (median time of 8 days before or after ERC, $n=42$ ). For beta-herpesviruses (CMV, HHV-6, HHV-7), we also tested available liver biopsies (median time of 38 days before or after ERC, $n=53$ ). Rates of herpesvirus positivity are shown in Table 2. HSV-1 and HSV-2 were rarely detected in bile (4.1 and $0 \%$, respectively), while there was a significant rate of detection in serum for at least HSV-1 (14.3\%). Varicella-zoster virus appeared to be rare after LT in serum (0\%) and bile (2.4\%), with only a single positive bile sample. EBV was often detected in bile (16.4\%) and serum samples (9.5\%). Cytomegalovirus is a pathogen known to be relevant after LT. It was significantly more prevalent in bile (18.3\%) than in serum samples $(2.4 \%)$ or liver tissue (0\%); this finding has been described before [4]. HHV-6 was highly prevalent in bile (34.2\%) and liver biopsies (15.1\%) but was rarely found in serum (2.4\%). The DNA copy number in bile was rather low, with a median copy number of 12.6 copies $/ \mathrm{ml}$ in HHV-6 positive patients whereas four patients had biliary HHV-6 DNA titers $>1000$ copies $/ \mathrm{ml}$. The median HHV-6 copy number in liver biopsy was 20 copies $/ \mathrm{ml}$ among those patients with amplifiable HHV-6 DNA. Only one patient in the liver biopsy group had a high copy number, that was over 1000 copies/ml. Liver biopsy and bile HHV-6 DNA copy number did not correlate significantly (Pearson correlation $r=-0.026, p=0.87$ ). HHV-7 was also highly prevalent in bile samples (20.5\%) but was not detected in serum $(0 \%)$ and rarely in liver biopsy (3.8\%) samples. HHV-6 and HHV-7 in bile correlated significantly (Pearson correlation $r=0.28, p=0.02$ )

Table 2 Herpesvirus prevalence after liver transplantation

\begin{tabular}{llll}
\hline & Bile & Serum & Liver Biopsy \\
\hline HSV-1 & $3 / 73(4.1 \%)$ & $6 / 42(14.3 \%)$ & \\
HSV-2 & $0 / 73(0 \%)$ & $1 / 42(2.4 \%)$ & \\
VZV & $1 / 72(1.4 \%)$ & $0 / 42(0 \%)$ & \\
EBV & $12 / 73(16.4 \%)$ & $4 / 42(9.5 \%)$ & \\
CMV & $13 / 71(18.3 \%)$ & $1 / 42(2.4 \%)$ & $0 / 51(0 \%)$ \\
HHV-6 & $25 / 73(34.2 \%)$ & $1 / 42(2.4 \%)$ & $8 / 53(15.1 \%)$ \\
HHV-7 & $15 / 73(20.5 \%)$ & $0 / 42(0 \%)$ & $2 / 53(3.8 \%)$ \\
HHV-8 & $1 / 64(1.6 \%)$ & & \\
\hline
\end{tabular}

CMV cytomegalovirus, EBV Epstein-Barr virus, HHV human herpesvirus, HSV herpes simplex virus, $V Z V$ varicella-zoster virus 
. HHV-6 reactivation due to HHV-7 infection has been described previously [15].

Of the 53 patients where HHV- 6 was tested in both bile and biopsy, 29/53 (54.7\%) tested concordantly negative, while 4/53 (7.5\%) tested concordantly positive, 16/ $53(30.2 \%)$ tested positive in bile but not in biopsy and $4 / 53$ tested positive in biopsy but not in bile (7.5\%) (Table 3). In chi-square test bile and biopsy positivity for HHV-6 were not significantly associated $(p=0.35)$, but those that tested concordantly positive where taken on significantly closer timepoints (median time between bile sample and biopsy was 3 days in concordantly positive bile and biopsy samples vs. median time of 21 days in non-concordant bile and biopsy samples).

We correlated HHV-6 with baseline characteristics and compared the prevalence of HHV- 6 positivity according to complications after liver transplantation. The labMELD score at the time of transplantation was significantly higher patients positive for HHV-6 in bile (16.4 vs. $22.5, p=0.02$, Table 4 ), while the eMELD score (36 patients) was similar in HHV-6 in bile positive and negative patients (27.6 vs. 27.3 , Table 4 ).

HHV-6 positivity in bile was also associated with the occurrence of allograft complications after LT. Nonanastomotic strictures (NAS) of the bile duct (41.7\% vs. $68.0 \%, p=0.03$, Table 4 ) and acute cellular rejection of the liver graft ( $16.6 \%$ vs. $44.0 \%, p=0.01$, Table 4$)$ were significantly more common in patients with HHV-6 positivity in bile. Patients positive for HHV-6 in bile were significantly more likely to also be positive for HHV-7 in bile (12.5\% HHV-7 pos. in HHV-6 neg. vs. $36.0 \%$ HHV-7 pos. in HHV-6 neg., $p=0.02$, Table 4). Surprisingly, HHV-6 positivity in bile did not correlate with HHV-6 positivity in serum samples or liver biopsy (Table 4). In addition, for the other herpesviruses, no correlation was observed between biliary positivity and biopsy or serum positivity (data not shown).

We assessed whether our patients had received valganciclovir as CMV prophylaxis at time of ERC. Valganciclovir was routinely administered for 6 months after LT to prevent CMV reactivation in the liver allograft. Valganciclovir prophylaxis did reduce the incidence of CMV positivity in bile (9.1\% vs. $27.8 \%, p=0.04$, Table 5$)$, but valganciclovir prophylaxis had no effect on the rate

Table 3 Concordance of HHV-6 positivity in bile and liver biopsy

\begin{tabular}{lllll}
\hline HHV-6 detection & & Bile & & \\
\cline { 3 - 4 } & & neg. & pos. & Total \\
\hline Biopsy & neg. & 29 & 16 & 45 \\
& pos. & 4 & 4 & 8 \\
& Total & 33 & 20 & 53 \\
\hline
\end{tabular}

Chi-square $=0.35$ of HHV-6 (38.2\% vs. $27 \%, p=0.25$, Table 5 ) or HHV-7positivity in bile $(17.6 \%$ vs. $18.9 \%, p=0.9$, Table 5$)$. The rate of EBV-positivity in bile ( $8.9 \%$ vs. $24.3 \%, p=0.07$, Table 5) was numerically reduced but did not reach statistical significance.

Patients that tested HHV-6 positive in bile were numerically more likely to die or undergo re-LT after ERC. Median survival after ERC for HHV-6 in bile positive versus HHV-6 in bile negative patients was 36.7 vs 86.7 months respectively (log-rank $p=0.01$, Fig. 2). There was no statistically significant difference noted for any other herpesvirus (Fig. 2). In univariate cox proportional hazard model HHV-6 in bile was negatively associated with retransplantation free survival (hazard ratio 2.72, $\mathrm{p}=0.01$ ). We included all know risk factors in the analysis and included them in a step up approach, when $p<0.1$. This led to the inclusion of time from LT to ERC, NAS, valganciclovir at ERC and HHV-7 in bile. In multivariate analysis HHV-6 in bile lost its significant negative association with retransplantation free survival (hazard ratio 2.15, $\mathrm{p}=0.07$ ), but remained the strongest risk factor for retransplantation or death among the included (Table 6).

\section{Discussion}

Biliary fluids can routinely be assessed after ERC but are rarely subject to scientific investigation. This is the first single-center case-control study to investigate herpesvirus $1-8$ prevalence in human bile samples and its association with biliary complications after LT. We found a high prevalence of CMV, HHV-6 and HHV-7 in biliary fluids in LT patients both with and without biliary complications. The rate of positivity of HHV-6 correlated with poor re-LT-free survival after ERC. The persistence of beta-herpesviruses in epithelia after LT has been described frequently [16]. Cytomegalovirus in bile has already been implicated in biliary lesion formation after LT, but its significance remains controversial $[4,17,18]$. Interestingly, in our study, the rates of detection of CMV, HHV-6 and HHV-7 in bile have been considerably higher than in serum or liver biopsies (Table 2). In bile we found the highest prevalence for HHV-6 (34.2\%) and HHV-7 (20.5\%) followed by CMV (18.3\%) and EBV (16.4\%) (Table 2). Presence of HHV-6 and HHV-7 often coincided possibly due to viral coactivation, as $9 / 15$ patients positive for HHV-7 in bile also tested positive for HHV-6 [19]. We found that patients with NAS and ACR were much more likely to test positive for HHV-6 and HHV-7 in bile than patients of the control group (Table 4). Interestingly, neither HHV-6 nor HHV-7 in liver biopsy or serum were associated with biliary complications after LT. In Kaplan-Meier analysis HHV-6 was significantly associated with death and retransplantation after ERC. This significance was lost however in multivariate 
Table 4 Characteristics of patients according to HHV-6 positivity in bile. Comparison of patients based on the main primary outcome parameter of retransplantation-free survival. Data is given as mean ( \pm SD), median (range) or number (\%), as appropriate

\begin{tabular}{|c|c|c|c|}
\hline & HHV-6 negative, $n=48(65.7 \%)$ & HHV-6 positive, $n=25$ (34.2\%) & $\mathrm{p}$ \\
\hline Gender, female (\%) & $8 / 48(16.7 \%)$ & $7 / 25(28.0 \%)$ & 0.20 \\
\hline Recipient Age (median, range), years & $55(30-69)$ & $59(41-66)$ & 0.36 \\
\hline Follow up (median, range), months & $39.5(2.0-91.2)$ & $20.7(0.6-102.9)$ & 0.78 \\
\hline Time of ERC (median, range), months & $3.5(0.3-73.6)$ & $2.4(0.3-22.1)$ & 0.38 \\
\hline Donor age (median, range), years & $60(21-88)$ & $61(27-82)$ & 0.65 \\
\hline eMELD at LT, points (mean \pm SD) & $27.6( \pm 5.3)$ & $27.3( \pm 4.9)$ & 0.87 \\
\hline labMELD at LT, points (mean $\pm S D$ ) & $16.4( \pm 9.5)$ & $22.5( \pm 12.2)$ & 0.02 \\
\hline Cold ischemia time,hours, (mean \pm SD) & $9.8( \pm 2.6)$ & $10.4( \pm 2.7)$ & 0.37 \\
\hline AS & 25/48 (48.1\%) & $9 / 25(36.0 \%)$ & 0.17 \\
\hline NAS & 20/48 (41.7\%) & $17 / 25(68.0 \%)$ & 0.03 \\
\hline Acute rejection & $8 / 48(16.6 \%)$ & $11 / 25(44.0 \%)$ & 0.01 \\
\hline CMV positivity in bile & $10 / 48(20.8 \%)$ & $3 / 23(13.0 \%)$ & 0.33 \\
\hline HHV-7 positivity in bile & $6 / 48(12.5 \%)$ & $9 / 25(36.0 \%)$ & 0.02 \\
\hline HHV-6 positivity in liver biopsy & $4 / 33(12.1 \%)$ & $4 / 20(20.0 \%)$ & 0.30 \\
\hline HHV-6 positivity in serum & $0 / 30(0 \%)$ & $1 / 11(9.1 \%)$ & 0.29 \\
\hline $\mathrm{AP}(\mathrm{U} / \mathrm{ml}, \mathrm{SD})$ & $194.1( \pm 125.4)$ & $195.6( \pm 153.8)$ & 0.96 \\
\hline Bilirubin (mg/ml, SD) & $6.2( \pm 9.3)$ & $7.6( \pm 8.8)$ & 0.52 \\
\hline AST (U/ml, SD) & $100.9( \pm 102.9)$ & $144.9( \pm 192.5)$ & 0.21 \\
\hline Leukocytes (cells/nl, SD) & $6.2( \pm 2.7)$ & $7.7( \pm 5.5)$ & 0.12 \\
\hline
\end{tabular}

AP: alkaline phosphatase, AS: anastomotic biliary stricture, AST: aspartate aminotransferase, CMV: cytomegalovirus, eMELD: exceptional model of end-stage liver disease, ERC: endoscopic retrograde cholangiopancreatography, HHV: human herpesvirus, LT: liver transplantation,labMELD: laboratory model of end-stage liver disease, NAS: non-anastomotic biliary stricture, SD: standard deviation

cox proportional hazard analysis after controlling for known risk factors such as type of stricture in the multivariate analysis (Fig. 2 and Table 6), however HHV-6 in bile remained the strongest risk factor for decreased reLT free survival among the included. If HHV-6 in bile is causally related to biliary strictures and thus graft survival or a mere bystander of damage of the biliary epithelium remains to be determined. We are not the first group to report the relation of HHV-6 and decreased graft survival. In a cohort of pediatric LT recipients chromosomally integrated HHV-6 DNA was associated with worse graft survival [20]. HHV-6 has also been associated with worse LT graft survival in an adult population after diagnosis of graft hepatitis with higher intrahepatic HHV-6 amplification levels [7]. The mechanism for this association remains unclear. However HHV-6 has been described to exert immunomodulatory effects such as increased secretion of interferon gamma, tumor-necrosis factor alpha or CCL5 [21-24]. HHV-6 has also been implicated in numerous autoimmune diseases such as multiple sclerosis, connective tissue disorders or autoimmune thyroiditis in part through molecular mimicry [25-29]. HHV-6 could thus exert immunomodulatory effects in the liver allograft leading to a host versus graft reaction leading to further damage of the biliary ducts.

The preexisting biliary damage of the donor organ at time of transplantation has been shown to predict subsequent risk for biliary complications [30]. We therefore assessed labMELD and cold ischemia time as established

Table 5 Valganciclovir and herpesvirus reactivation. Data is given as number (\%)

\begin{tabular}{llll}
\hline & LT recipients $(n=71)$ & & \\
\cline { 2 - 4 } & Valganciclovir prophylaxis $(n=34)$ & No Valganciclovir prophylaxis $(n=37)$ & $9 / 37(24.3 \%)$ \\
\hline EBV positive & $3 / 34(8.9 \%)$ & $10 / 36(27.8 \%)$ & 0.07 \\
CMV positive & $3 / 33(9.1 \%)$ & $10 / 37(27 \%)$ & 0.04 \\
HHV-6 positive & $13 / 34(38.2 \%)$ & $7 / 37(18.9 \%)$ & 0.25 \\
HHV-7 positive & $6 / 34(17.6 \%)$ & 0.9 \\
\hline
\end{tabular}

CMV cytomegalovirus, EBV Epstein-Barr virus, HHV human herpesvirus, HSV herpes simplex virus, $L T$ liver transplantation, $V Z V$ varicella-zoster virus 
A

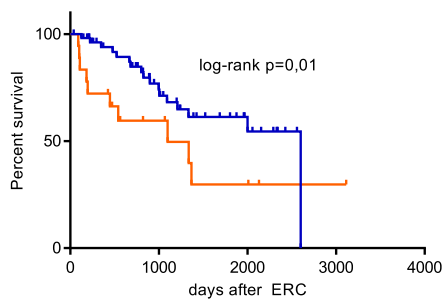

C

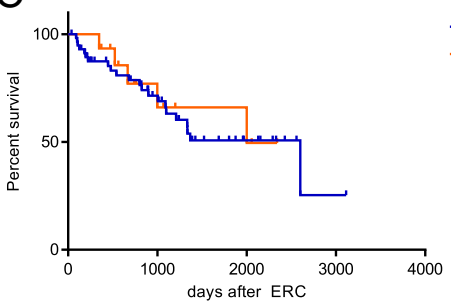

B
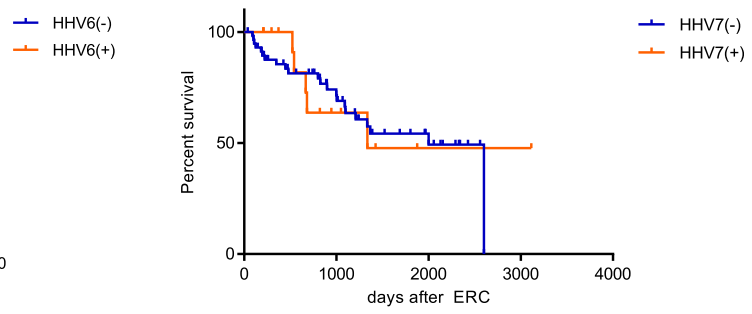

D
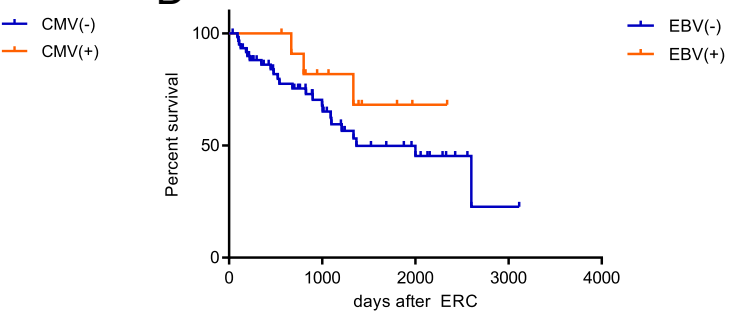

Fig. 2 Retransplantation free survival after ERC according to herpesvirus positivity in bile. Comparison of retransplantation free survival after ERC according to herpesvirus positivity in bile, comparison with log-rank. A Human herpesvirus 6 (HHV-6) B Human Herpesvirus 7 (HHV-7) C Cytomegalovirus (CMV) D Epstein-Barr-Virus (EBV)

risk factors for mortality and associated with early allograft loss, which were evenly distributed in our study.

Increased recipient morbidity at time of transplantation likewise seems to play a role for biliary HHV-6 infections. We recorded labMELD score at transplantation as a surrogate marker for recipient morbidity at transplantation [31]. Patients positive for HHV-6 in bile had a higher median labMELD (16.4 vs. $22.5, p=0.02$, Table 4 ) but not a higher eMELD score at LT. Patients with a higher labMELD score at the time of transplantation presented more severe hepatic and renal impairment. This precondition might predispose patients to opportunistic infections and, in our study, might in part explain the increased prevalence of herpesvirus infections. The association of HHV-6 with graft complications and reduced survival poses the important question of

Table 6 Uni- and multivariate analysis of risk factors for graft loss or death

\begin{tabular}{|c|c|c|c|c|}
\hline & \multicolumn{2}{|l|}{ Univariate } & \multicolumn{2}{|l|}{ Multivariate } \\
\hline & Hazard ratio $(95 \% \mathrm{Cl})$ & $\mathrm{p}$ & Hazard ratio $(95 \% \mathrm{Cl})$ & $p$ \\
\hline HSV-1 positivity (bile) & $2.34(0.70-7,80)$ & 0.17 & & \\
\hline HSV-1 positivity (serum) & $0.43(0.06-3.49)$ & 0.39 & & \\
\hline EBV positivity (bile) & $0.82(0.28-2.38)$ & 0.72 & & \\
\hline EBV positivity (serum) & $2.18(0.47-10.02)$ & 0.32 & & \\
\hline CMV positivity (bile) & $0.21(0.29-1.58)$ & 0.13 & & \\
\hline HHV-6 positivity (bile) & $2.72(1.25-5.90)$ & 0.01 & $2.15(0.94-4.95)$ & 0.07 \\
\hline HHV-6 positivity (liver biopsy) & $1.02(0.30-3.46)$ & 0.98 & & \\
\hline HHV-7 positivity (bile) & $2.57(1.14-5.78)$ & 0.02 & $2.03(0.81-5.12)$ & 0.13 \\
\hline Valganciclovir at time of ERC & $1.78(0.97-3.26)$ & 0.07 & $0.99(0.48-2.07)$ & 0.87 \\
\hline Time between LT and ERC [months] & $0.93(0.86-1.01)$ & 0.08 & $0.94(0.79-1.12)$ & 0.27 \\
\hline NAS vs. AS/control & $1.74(0.99-3.05)$ & 0.05 & $0.94(0.79-1.12)$ & 0.47 \\
\hline Recipient age, years & $1.02(0.97-1.07)$ & 0.49 & & \\
\hline Donor age, years & $1.02(0.99-1.04)$ & 0.18 & & \\
\hline MELD score at LT & $0.94(0.81-1.01)$ & 0.12 & & \\
\hline Cold ischemia time & $0.96(0.83-1.11)$ & 0.39 & & \\
\hline
\end{tabular}

$A S$, anastomotic biliary stricture, $C M V$ cytomegalovirus, EBV Epstein-Barr virus, $H H V$ human herpesvirus, $E R C$ endoscopic retrograde cholangiopancreatography, $H S V$ herpes simplex virus, $L T$ liver transplantation, MELD model of end-stage liver disease, NAS non-anastomotic biliary stricture, VZV varicella-zoster virus 
possible prevention of HHV-6 reactivation/infection. Interestingly, valganciclovir prophylaxis did not reduce the incidence of HHV- 6 prevalence nor the mean viral count in bile $(38.2 \%$ vs. $27 \%, p=0.25$, Table 5$)$. This might be due to a lower responsiveness of HHV-6 and HHV-7 than CMV to valganciclovir or ganciclovir treatment [32]. In a study by Humar et al. of CMV, HHV-6 and HHV-7 coinfected patients, valganciclovir treatment did reduce the CMV but not the HHV-6 and HHV-7 viral load [32]. Consistent in our study CMV prophylaxis was sufficient in our patients to prevent CMV infection. This might explain why in our study CMV in bile was not related to NAS, contrasting with prior data published by our group [4]. In the current study, bile retrieval was undertaken early after LT while many patients $(47.8 \%)$ were under CMV prophylaxis. When excluding patients on prophylactic therapy, there was a numerical though statistically insignificant higher prevalence of non-anastomotic strictures in patients who tested positive for CMV in bile ( $50 \%$ vs. $33 \%$, ns).

Two important findings conclude our study. The first is the striking discrepancy of herpesvirus detection of the different compartments (bile, serum, tissue). Currently, blood serum is used for routine HHV-6 detection; indeed biliary samples might be more sensitive and specific for HHV-6 detection in the liver allograft. This finding is not limited to herpesviruses but might extend to all DNA-viruses and bacteria. We thus hypothesize that testing biliary fluid might mirror local infective processes of the hepatobiliary compartment with a higher sensitivity than serum or biopsy specimen. The second important finding is the correlation between locoregional HHV-6 (and possibly CMV in the later course) detection and severe liver allograft complications. We further hypothesize that routine CMV prophylaxis with valganciclovir is not sufficient to prevent HHV-6 (and HHV-7) infection, which raises important questions for clinical practice $[33,34]$.

Our study however poses several important limitations. HHV-6 positivity in bile did not significantly correlate with positivity in the liver biopsy. Even samples with very high virus counts in bile that where taken on subsequent days to the liver biopsy showed no virus amplification in the biopsy tissue. It could be possible, that the liver biopsy was non representative of the donor organ. The focal distribution of HHV-6 in infected liver tissue is not known. The design of the study was a retrospective case-control study wherein different cohorts were randomly selected from a tissue and fluid biobank. Concordant biopsy, serum and bile samples were not always available, and when they were available, they were not always taken on the same day.

The methods for DNA detection were not established for biliary fluids, and stability data on viral DNA in biliary fluid is lacking. Furthermore, viral loads for HHV-6 were low. Only 4 out of 25 patients had viral loads $>1000$ copies $/ \mathrm{ml}$, the threshold for consideration as an active HHV-6 infection in serum samples [35]. While this finding could reflect a high percentage of latent infection and explain why viral DNA in those cases could not be detected in serum samples from the same recipients, this could also be due to DNA degradation in our bile samples. Our study warrants further exploration in a prospective experimental setting. If confirmed, treatment of occult HHV-6 and HHV-7 infection in cases of sustained and progressive biliary damage after LT might lead to a reduced risk of graft loss and need for re-LT. Further understanding of the role of non-CMV betaherpesviruses in LT might also affect recommendations for the routine use of valganciclovir in the initial months after LT.

\section{Conclusion}

The present study shows that CMV, EBV and HHV-6 and -7 are highly prevalent in biliary fluid. Overall betaherpesvirus detection was more frequent in bile than in liver biopsy or serum. HHV-6 is associated with biliary complications after LT. Further studies are needed to assess the potential connection of HHV- 6 detection in bile and biliary complications after LT and the general value of routine viral diagnostics in bile compared to serum and liver biopsy.

\section{Abbreviations \\ ACR: Acute cellular rejection; AS: Anastomotic biliary stricture: \\ CMV: Cytomegalovirus; EBV: Epstein-Barr virus; eMELD: Exceptional model of end-stage liver disease; ERC: Endoscopic retrograde cholangiography; HCC: Hepatocellular carcinoma; HHV: Human herpesvirus; \\ labMELD: Laboratory model of end-stage liver disease; LT: Liver transplantation; NAS: Non-anastomotic biliary stricture; PCR: Polymerase chain reaction; qPCR: Quantative polymerase chain reaction; SD: Standard deviation; Th1: T-Helper cell Type 1; VZV: Varicella-zoster virus}

\section{Acknowledgments}

We would like to acknowledge the financial support of University Hospital Heidelberg. We acknowledge Petra Kloeters-Plachky for her help with the technical procedures. We thank our interdisciplinary unit of endoscopy for the bile sampling.

\section{Authors' contributions}

DNG conceived the study and provided intellectual guidance; CoR provided the study design, analyzed the data and wrote the paper; KB performed the experiments and analyzed the data and revised the script; ChR, KHW, PaS, PeS1, PeS2 and TZ provided intellectual guidance and revised the manuscript. All authors read and approved the final manuscript.

\section{Funding}

Funding for this study was provided by the University Hospital Heidelberg. We acknowledge financial support by Deutsche Forschungsgemeinschaft within the funding programme Open Access Publishing, by the BadenWürttemberg Ministry of Science, Research and the Arts and by RuprechtKarls-Universität Heidelberg. The funding bodies had no role in the design of the study and collection, analysis, and interpretation of the data and in writing the manuscript. 


\section{Availability of data and materials}

The datasets used and/or analyzed during the current study are available from the corresponding author on reasonable request.

\section{Ethics approval and consent to participate}

Written informed consent was obtained for all subjects. This work was granted ethical approval by the University Hospital Heidelberg ethics committee 566 (Nr. S-043/2011). A Free and Informed Consent Form was read and signed by the patients who participated in this study.

\section{Consent for publication}

Not applicable.

\section{Competing interests}

All authors declare that they have no competing interests.

\section{Author details}

'Department of Gastroenterology and Hepatology, University Hospital Heidelberg, Heidelberg, Germany. ${ }^{2}$ Department of General, Visceral and Transplant Surgery, University Hospital Heidelberg, Heidelberg, Germany. ${ }^{3}$ Department of Virology, University Hospital Heidelberg, Heidelberg, Germany. ${ }^{4}$ Department of Surgery, Division of Transplant Surgery, Medical University of Graz, Graz, Austria. ${ }^{5}$ INSERM U1015, Gustave Roussy Comprehensive Cancer Institute, Villejuif, France.

\section{Received: 22 October 2018 Accepted: 21 June 2019}

\section{Published online: 27 June 2019}

\section{References}

1. Gimeno C, Solano C, Latorre JC, Hernández-Boluda JC, Clari MA, Remigia MJ, et al. Quantification of DNA in plasma by an automated real-time PCR assay (cytomegalovirus PCR kit) for surveillance of active cytomegalovirus infection and guidance of preemptive therapy for allogeneic hematopoietic stem cell transplant recipients. J Clin Microbiol. 2008;46:3311-8.

2. Mendez JC, Dockrell DH, Espy MJ, Smith TF, Wilson JA, Harmsen WS, et al. Human beta-herpesvirus interactions in solid organ transplant recipients. J Infect Dis. 2001:183:179-84.

3. Aberg F, Mäkisalo H, Höckerstedt K, Isoniemi H. Infectious complications more than 1 year after liver transplantation: a 3-decade nationwide experience. Am J Transplant Off J Am Soc Transplant Am Soc Transpl Surg. 2011;11:287-95.

4. Gotthardt DN, Senft J, Sauer P, Weiss KH, Flechtenmacher C, Eckerle I, et al. Occult cytomegalovirus cholangitis as a potential cause of cholestatic complications after orthotopic liver transplantation? A study of cytomegalovirus DNA in bile. Liver Transplant Off Publ Am Assoc Study Liver Dis Int Liver Transplant Soc. 2013:19:1142-50.

5. Lautenschlager I, Höckerstedt K, Linnavuori K, Taskinen E. Human herpesvirus-6 infection after liver transplantation. Clin Infect Dis Off Publ Infect Dis Soc Am. 1998;26:702-7.

6. Razonable RR, Zerr DM. AST Infectious Diseases Community of Practice. HHV-6, HHV-7 and HHV-8 in solid organ transplant recipients. Am J Transplant Off J Am Soc Transplant Am Soc Transpl Surg. 2009;9(Suppl 4): S97-100.

7. Pischke S, Gösling J, Engelmann I, Schlue J, Wölk B, Jäckel E, et al. High intrahepatic HHV-6 virus loads but neither CMV nor EBV are associated with decreased graft survival after diagnosis of graft hepatitis. J Hepatol. 2012;56: 1063-9.

8. Buyse S, Roque-Afonso A-M, Vaghefi P, Gigou M, Dussaix E, Duclos-Vallée J$C$, et al. Acute hepatitis with periportal confluent necrosis associated with human herpesvirus 6 infection in liver transplant patients. Am J Clin Pathol. 2013;140:403-9.

9. Phan TL, Lautenschlager I, Razonable RR, Munoz FM. HHV-6 in liver transplantation: a literature review. Liver Int Off J Int Assoc Study Liver. 2018; 38:210-23

10. Owers DS, Webster AC, Strippoli GFM, Kable K, Hodson EM. Pre-emptive treatment for cytomegalovirus viraemia to prevent cytomegalovirus disease in solid organ transplant recipients. Cochrane Database Syst Rev. 2013;: CD005133.

11. De Clercq E, Naesens L, De Bolle L, Schols D, Zhang Y, Neyts J. Antiviral agents active against human herpesviruses HHV-6, HHV-7 and HHV-8. Rev Med Virol. 2001;11:381-95.
12. Jochmans I, van Rosmalen M, Pirenne J, Samuel U. Adult liver allocation in Eurotransplant. Transplantation. 2017:101:1542-50.

13. Wiesner R, Edwards E, Freeman R, Harper A, Kim R, Kamath $P$, et al. Model for end-stage liver disease (MELD) and allocation of donor livers. Gastroenterology. 2003;124:91-6.

14. Umgelter A, Hapfelmeier A, Kopp W, van Rosmalen M, Rogiers X, Guba M, et al. Disparities in Eurotransplant liver transplantation wait-list outcome between patients with and without model for end-stage liver disease exceptions. Liver Transplant Off Publ Am Assoc Study Liver Dis Int Liver Transplant Soc. 2017;23:1256-65.

15. Katsafanas GC, Schirmer EC, Wyatt LS, Frenkel N. In vitro activation of human herpesviruses 6 and 7 from latency. Proc Natl Acad Sci U S A. 1996;93:9788-92

16. Halme L, Arola J, Höckerstedt K, Lautenschlager I. Human herpesvirus 6 infection of the gastroduodenal mucosa. Clin Infect Dis Off Publ Infect Dis Soc Am. 2008:46:434-9.

17. Kowdley KV, Fawaz KA, Kaplan MM. Extrahepatic biliary stricture associated with cytomegalovirus in a liver transplant recipient. Transpl Int Off J Eur Soc Organ Transplant. 1996;9:161-3.

18. Bittermann T, Goldberg DS. Cytomegalovirus and posttransplant biliary complications: elusive offender or innocent bystander? Liver Transplant Off Publ Am Assoc Study Liver Dis Int Liver Transplant Soc. 2013;19:1062-4.

19. Härmä M, Höckerstedt K, Lyytikäinen O, Lautenschlager I. HHV-6 and HHV-7 antigenemia related to CMV infection after liver transplantation. J Med Virol. 2006;78:800-5

20. Lee S-O, Brown RA, Razonable RR. Clinical significance of Pretransplant chromosomally integrated human Herpesvirus-6 in liver transplant recipients. Transplantation. 2011;92:224-9.

21. Inagi R, Guntapong $R$, Nakao M, Ishino $Y$, Kawanishi K, Isegawa $Y$, et al. Human herpesvirus 6 induces IL-8 gene expression in human hepatoma cell line, Hep G2. J Med Virol. 1996:49:34-40.

22. Dagna L, Pritchett JC, Lusso P. Immunomodulation and immunosuppression by human herpesvirus 6A and 6B. Future Virol. 2013:8:273-87.

23. Grivel JC, Ito Y, Fagà G, Santoro F, Shaheen F, Malnati MS, et al. Suppression of CCR5- but not CXCR4-tropic HIV-1 in lymphoid tissue by human herpesvirus 6. Nat Med. 2001;7:1232-5.

24. Flamand L, Gosselin J, D'Addario M, Hiscott J, Ablashi DV, Gallo RC, et al. Human herpesvirus 6 induces interleukin-1 beta and tumor necrosis factor alpha, but not interleukin-6, in peripheral blood mononuclear cell cultures. J Virol. 1991:65:5105-10.

25. Zahednasab H, Keyvani H, Karampour S, Harirchian MH. Role of HHV-6 subtypes in accelerating EAE progression. Proc Natl Acad Sci U S A. 2018;115:E12126.

26. Alvarez-Lafuente R, García-Montojo M, De las Heras V, Bartolomé M, Arroyo R. Clinical parameters and HHV-6 active replication in relapsing-remitting multiple sclerosis patients. J Clin Virol Off Publ Pan Am Soc Clin Virol. 2006; 37(Suppl 1):S24-6.

27. Broccolo F, Drago F, Paolino S, Cassina G, Gatto F, Fusetti L, et al. Reactivation of human herpesvirus 6 (HHV-6) infection in patients with connective tissue diseases. J Clin Virol Off Publ Pan Am Soc Clin Virol. 2009;46:43-6.

28. Grima $P$, Chiavaroli R, Calabrese P, Tundo P, Grima P. Severe hepatitis with autoimmune features following a HHV-6: a case report. Cases J. 2008;1:110

29. Tejada-Simon MV, Zang YCQ, Hong J, Rivera VM, Zhang JZ. Cross-reactivity with myelin basic protein and human herpesvirus-6 in multiple sclerosis. Ann Neurol. 2003:53:189-97.

30. Brunner SM, Junger H, Ruemmele P, Schnitzbauer AA, Doenecke A, Kirchner Gl, et al. Bile duct damage after cold storage of deceased donor livers predicts biliary complications after liver transplantation. J Hepatol. 2013;58:1133-9.

31. Klein KB, Stafinski TD, Menon D. Predicting survival after liver transplantation based on pre-transplant MELD score: a systematic review of the literature. PLoS One. 2013;8:e80661.

32. Humar A, Asberg A, Kumar D, Hartmann A, Moussa G, Jardine A, et al. An assessment of herpesvirus co-infections in patients with CMV disease: correlation with clinical and virologic outcomes. Am J Transplant Off J Am Soc Transplant Am Soc Transpl Surg. 2009;9:374-81.

33. Wen J, Xiao Y, Wang J, Pan W, Zhou Y, Zhang X, et al. Low doses of CMV induce autoimmune-mediated and inflammatory responses in bile duct epithelia of regulatory T cell-depleted neonatal mice. Lab Investig J Tech Methods Pathol. 2015;95:180-92.

34. Akamatsu N, Sugawara Y, Hashimoto D. Biliary reconstruction, its complications and management of biliary complications after adult live transplantation: a systematic review of the incidence, risk factors and outcome. Transpl Int Off J Eur Soc Organ Transplant. 2011;24:379-92. 
35. de Pagter PJA, Schuurman R, Visscher H, de Vos M, Bierings M, van Loon AM, et al. Human herpesvirus 6 plasma DNA positivity after hematopoietic stem cell transplantation in children: an important risk factor for clinical outcome. Biol Blood Marrow Transplant J Am Soc Blood Marrow Transplant. 2008; 14:831-9.

\section{Publisher's Note}

Springer Nature remains neutral with regard to jurisdictional claims in published maps and institutional affiliations.

Ready to submit your research? Choose BMC and benefit from:

- fast, convenient online submission

- thorough peer review by experienced researchers in your field

- rapid publication on acceptance

- support for research data, including large and complex data types

- gold Open Access which fosters wider collaboration and increased citations

- maximum visibility for your research: over $100 \mathrm{M}$ website views per year

At $B M C$, research is always in progress.

Learn more biomedcentral.com/submissions 